\title{
A Cross-sectional Observational Analysis of Preoperative Blood Glucose Levels in Nondiabetic Patients presenting for Surgery
}

\author{
${ }^{1}$ Swagat Pattajoshi, ${ }^{2}$ Aparna A Nerurkar, ${ }^{3}$ Bharati A Tendolkar
}

\begin{abstract}
Introduction: Abnormal blood glucose levels alter the course and result of surgery. This study aims to quantify the incidence of hypoglycemia or hyperglycemia in the preoperative period and to assess the impact of duration of nil per os (NPO), age, intravenous fluids (IVFs), blood transfusion, severity of pain and anxiety, and steroid or antibiotic administration on preoperative blood glucose levels in nondiabetic patients.
\end{abstract}

Materials and methods: The NPO duration, age, IVF, blood transfusion, pain and anxiety score, steroid and antibiotic administration were noted in 1,000 nondiabetic patients presenting for both elective and emergency surgery. Blood glucose level was measured before induction of anesthesia by capillary finger-prick method. The values of blood glucose levels were analyzed for correlation with above-mentioned parameters.

Results: Overall incidence of hypoglycemia was found to be $23.3 \%$. About $27.2 \%$ of patients including $34.95 \%$ children posted for elective surgery and $33.37 \%$ of patients including $8.73 \%$ children posted for emergency surgery group were hypoglycemic. The incidence of hyperglycemia was 1.51 and $1.08 \%$ for adults in elective and emergency category respectively. Age showed widely varied association to preoperative blood glucose levels; blood glucose levels increased with age in male patients, with patients aged between 18 and 40 years admitted for emergency surgery $(p=0.006)$, but decreased with age in patients older than 60 years irrespective of gender and type of surgery $(p=0.014)$. The preoperative blood glucose levels increased with higher preoperative pain and anxiety $(p=0.05)$ and administration of steroids $(p=0.00043)$. Similarly, with increase in duration of NPO, preoperative blood glucose levels decreased in adult females $(p=0.000)$ and males over 40 years $(p=0.049)$, both admitted for emergency surgery. Only preoperative normal saline (NS; $p=0.001), 6 \%$ hydroxyethyl

\footnotetext{
${ }^{1}$ Specialist Medical Officer, ${ }^{2}$ Additional Professor, ${ }^{3}$ Professor and Head

${ }^{1}$ Department of Anesthesia, Hinduhridaysamrat Balasaheb Thackeray Medical College and Dr. Rustom Narsi Cooper Municipal General Hospital, Mumbai, Maharashtra, India

${ }^{2,3}$ Department of Anesthesiology, Lokmanya Tilak Municipal General Hospital and Lokmanya Tilak Municipal Medical College, Mumbai, Maharashtra, India
}

Corresponding Author: Aparna A Nerurkar, Additional Professor, Department of Anesthesiology, Lokmanya Tilak Municipal General Hospital and Lokmanya Tilak Municipal Medical College, Mumbai, Maharashtra, India, Phone: +919833944243, e-mail: draparnanerurkar@gmail.com starch (HES; $p=0.043)$, Isolyte P $(p=0.000)$, and blood transfusion $(p=0.05)$ showed significant correlation.

Conclusion: Preoperative blood glucose monitoring is recommended mandatorily for all patients posted for emergency surgery. It is also recommended for elective pediatric and geriatric surgery patients, patients with high anxiety and/or pain, increased NPO duration, and preoperative administration of steroid, NS, $6 \%$ HES, or blood.

Keywords: Age, Anxiety, Blood glucose, Blood sugar, Intravenous fluids, Nil by mouth, Nil per os, Nondiabetic, Pain, Preoperative, Steroids.

How to cite this article: Pattajoshi S, Nerurkar AA, Tendolkar BA. A Cross-sectional Observational Analysis of Preoperative Blood Glucose Levels in Nondiabetic Patients presenting for Surgery. Res Inno in Anesth 2017;2(2):29-33.

Source of support: Nil

Conflict of interest: None

\section{INTRODUCTION}

Abnormal blood glucose levels alter the course and result of surgery. Preoperative hypoglycemia results in neuroendocrine stimulation by central nervous systemmediated sympatheticoadrenal discharge. ${ }^{1}$ Similarly, preoperative hyperglycemia prolongs wound healing and increases the chances of infection. ${ }^{2}$ Various factors affecting the blood sugar levels in the preoperative period include age, ${ }^{3-6}$ duration of starvation, ${ }^{3,6}$ operative and anesthesia stress, ${ }^{7,8}$ steroid use, ${ }^{9-12}$ antibiotic given, ${ }^{13-17}$ as also type and amount of IVFs given. ${ }^{18-22}$ However, it is not a routine practice to measure blood glucose perioperatively in nondiabetic patients. Relatively inexpensive, point-of-care blood glucose monitors, which are easy to use and show good correlation with laboratory values, have become available.

Hence, this study aimed to estimate the incidence of hypoglycemia and hyperglycemia in preoperative nondiabetic patients posted for surgery as well as to analyze the impact of factors mentioned above on preoperative blood glucose levels.

\section{MATERIALS AND METHODS}

The study was approved by the institutional ethics committee and registered at Clinical Trial Registry of India 
(CTRI/2017/09/009713). Considering surgical patient population to be 954 per 100,000 population in the year 2012 to 2013 with total population of 1.28 billion for Indian context, with a confidence interval of 4 and confidence level of 95 to $99 \%$; the sample size was estimated to be 839 to 1,210. Sample size was decided as 1,000 and all consenting patients of either sex and any American Society of Anesthesiologists (ASA) class, between age 1 and 90 years, admitted for various elective or emergency surgeries during the period April 2014 to August 2015, at the study institute were included in the study. Infants, pregnant and lactating females, uncooperative patients, patients on IVFs for more than 24 hours, patients where IV access could not be secured prior to induction of anesthesia, patients with diabetes mellitus, patients with other endocrine disorders known to affect blood sugar levels were excluded from the study. We used convenient, consenting, consecutive sampling method for collection of data.

The demographic details, duration of preoperative NPO, any IVFs/blood transfusion, steroid administration, and antibiotic given were collected. The NPO span was calculated from the time of last oral ingestion, excluding sips of water for oral medication purpose. The subjective assessment of anxiety and pain was calculated from Numerical Analog Scale for pain and anxiety, with 1 for the minimal pain/anxiety and 5 for the maximum extreme. The blood sample was collected preoperatively by capillary finger-prick method. Blood glucose levels were measured with the help of a Glucometer (One Touch Select Simple Blood Glucose Monitor, Johnson and Johnson Private Ltd, Mumbai, Maharashtra, India) and recorded in milligram per deciliter.

The data were compiled in Excel sheet and statistically analyzed using software version Statistical Package for the Social Sciences 12.0 (SPSS Inc., Chicago, Illinois).

\section{Statistical Analysis}

All continuous variables like age, duration of starvation, and blood glucose levels were assessed for normality and were log transformed if not found to be distributed normally, to make the data best fit for reliable interpretability. The numerical anxiety and pain scale were considered as the categorical variables. Administration of preoperative steroids, preoperative blood transfusion, and infusion of $6 \%$ HES was interpreted as binary variables (the data presented as 1 or 0 for YES or NO respectively). The numerical data were subdivided into different subgroups and transformed to categorical data for ease of multiple statistical analysis. Pearson correlation and Student's t-test were used to test the bivariate association of the above-mentioned continuous and binary variables, respectively, with preoperative blood glucose levels. Analysis of variance (ANOVA) and multiple linear regression model were used to test the association of the categorical variables. Data were assessed for colinearity before possible inclusion in multiple linear regression model. A p-value $<0.05$ was considered to be significant, $<0.01$ highly significant, and $<0.001$ very highly significant for all statistical comparisons.

\section{RESULTS}

The demographic characteristics of the study population are presented in Table 1.

The mean duration of preoperative fasting (Table 2) was 11.872 hours with a range from 4 to 48 hours. About $52.4 \%$ of patients were NPO for more than 10 hours; $64.4 \%$ of patients were infused some kind of IVFs during NPO hours, which included 9.2\% with dextrose normal saline (DNS) and 6.5\% with blood transfusion. Anxiety and pain scores were as follows: I for $18.10 \%$, II for $34.9 \%$, III for $31.8 \%$, IV for $15 \%$, and V for $0.2 \%$ of population. Only $2.9 \%$ of total study population had received steroid injections for different indications. None of the patients in the study were administered any antibiotic that has a known action on glucose metabolism.

In our study, $15.15 \%$ of adults and $34.95 \%$ of children from elective surgery group and $24.64 \%$ of adults and $8.73 \%$ of children in emergency surgery group were hypoglycemic (Table 3). Overall incidence of hypoglycemia

Table 1: Demographic characteristics

\begin{tabular}{ll}
\hline Parameters & Distribution \\
\hline Adult (>18-90 years): Pediatric (1-18 years) & $688: 312$ \\
Elective: Emergency & $318: 682$ \\
Male: Female & $747: 253$ \\
ASA class I/II/III & $837 / 150 / 13$ \\
\hline
\end{tabular}

Table 2: Duration of preoperative starvation

\begin{tabular}{clll}
\hline Duration (in hours) & Frequency & Mean \pm SD & Percentage \\
\hline $4-6$ & 39 & $5.59 \pm 0.71$ & 3.9 \\
$>6-8$ & 186 & $7.69 \pm 0.46$ & 18.6 \\
$>8-10$ & 251 & $9.53 \pm 0.5$ & 25.1 \\
$>10-12$ & 236 & $11.5 \pm 0.5$ & 23.6 \\
$>12-24$ & 254 & $16.1 \pm 3.57$ & 25.4 \\
$>24$ & 34 & $30.2 \pm 7.68$ & 3.4 \\
\hline
\end{tabular}

SD: Standard deviation

Table 3: Incidence of hypoglycemia

\begin{tabular}{llllll}
\hline \multirow{2}{*}{$\begin{array}{l}\text { Age of patient } \\
\text { (in years) }\end{array}$} & \multicolumn{2}{c}{ In elective surgery } & & \multicolumn{2}{c}{ In emergency surgery } \\
\cline { 2 - 3 } \cline { 5 - 6 } & Incidence & Percentage & & Incidence & Percentage \\
\hline Adult $(>18)$ & $20 / 132$ & 15.15 & $137 / 556$ & 24.64 \\
Pediatric (1-18) & $65 / 186$ & 34.95 & & $11 / 126$ & 8.73 \\
\hline
\end{tabular}




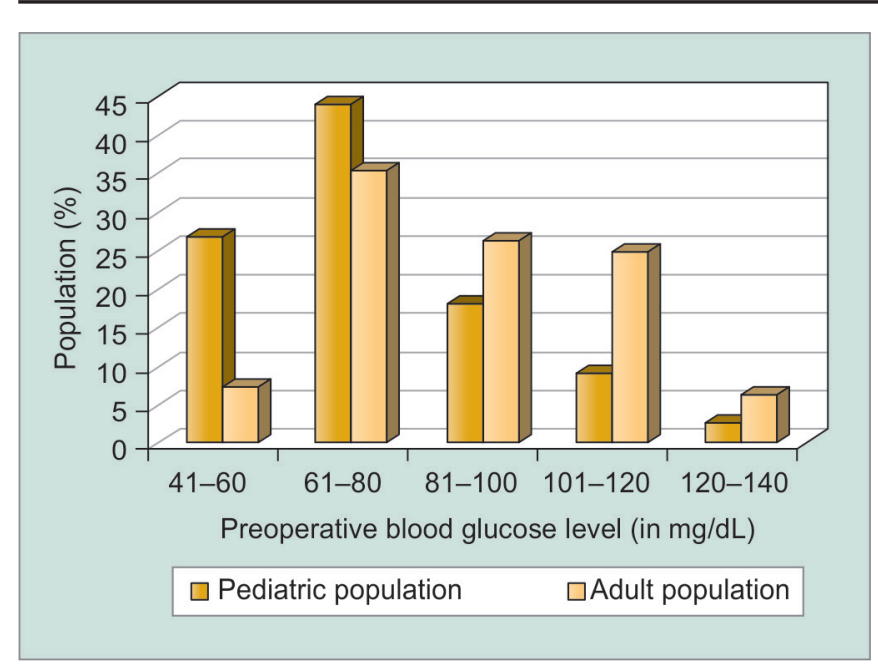

Graph 1: Preoperative blood glucose levels in pediatric vs adult patients

in adults was 22.81 and $24.35 \%$ in children (Graph 1). Similarly, 1.15 and $1.08 \%$ of adults in elective and emergency surgery study group respectively, were hyperglycemic. None of the children were hyperglycemic.

The difference of mean blood glucose level (Tables 4 and 5$)$ is significantly correlated with age $(p=0.000)$, type of surgery $(p=0.000)$, administration of Isolyte $P$ $(\mathrm{p}=0.000)$, duration of starvation $(\mathrm{p}=0.0092)$, anxiety $(p=0.0023)$, and pain $(p=0.000)$. Steroid recipients show a higher blood glucose levels $(\mathrm{p}=0.00043)$.

Subgroup analysis using ANOVA and multiple linear regression was done. Male patients, aged 18 to 40 years, presenting for emergency surgery showed an increase in blood glucose values as age increased $(p=0.006)$, preoperative $6 \%$ HES (p-value $=0.043)$, or steroid $(p=0.000)$ was administered, and as pain and anxiety score increased $(p=0.000)$. Blood glucose levels showed a fall with preoperative NS infusion ( $p=0.001)$, age more than 40 years with increased duration of starvation $(p=0.049)$. Female patients, aged more than 18 years, posted for emergency surgery showed a fall in blood glucose values with increased duration of starvation $(p=0.000)$ and preoperative $6 \%$ HES infusion (negative, $p=0.01$ ) but an increase with preoperative blood transfusion $(\mathrm{p}=0.05)$ and higher anxiety and pain scores $(\mathrm{p}=0.01)$. Patients more than 60 years of age, of either sex, irrespective of surgical indication showed a decrease in blood glucose values with increasing age $(\mathrm{p}=0.014)$.

\section{DISCUSSION}

Blood glucose levels show a wide range of fluctuations in the perioperative period. Perioperative dysglycemia is recognized as one of the risk factors of increased morbidity and mortality during and after surgery. ${ }^{23}$ Preoperative hypoglycemia results in neuroendocrine stimulation and may lead to behavioral changes, confusion, seizure,
Table 4: Comparative analysis of outcomes of categorical variables (age, sex, type of surgery, and IVFs) on blood glucose level

\begin{tabular}{lll}
\hline & $\begin{array}{l}\text { Mean diff. of blood } \\
\text { glucose in } \mathrm{mg} / \mathrm{dL}\end{array}$ & $p$-value \\
\hline Age (adults vs pediatrics) & $6.422 \pm 1.088$ & $0.000^{\mathrm{a}}$ \\
Sex (male vs female) & $0.0719 \pm 1.1$ & 0.9479 \\
Surgery (elective vs emergency) & $8.225 \pm 1.394$ & $0.000^{\mathrm{a}}$ \\
$\mathrm{NS}$ (given vs not given) & $1.535 \pm 1.332$ & 0.2495 \\
$\mathrm{RL}$ (given vs not given) & $2.521 \pm 1.601$ & 0.1155 \\
DNS (given vs not given) & $0.364 \pm 2.286$ & 0.1802 \\
HES (given vs not given) & $5.001 \pm 3.695$ & 0.5578 \\
Isolyte P (given vs not given) & $21.91 \pm 1.708$ & $0.000^{\mathrm{a}}$ \\
Blood (given vs not given) & $5.195 \pm 2.651$ & 0.1210 \\
\hline
\end{tabular}

avery highly significant

Table 5: Comparative analysis of duration of starvation, ASA grade, and anxiety and pain scale on blood glucose level

\begin{tabular}{ll}
\hline Parameters & $p$-value \\
\hline Duration of starvation & $0.0092^{\mathrm{a}}$ \\
ASA grade & 0.0897 \\
Anxiety and pain scale & $0.0023^{\mathrm{a}}$ \\
\hline
\end{tabular}

aHighly significant

palpitation, tremor, anxiety, diaphoresis, pallor, etc. On the contrary, preoperative hyperglycemia prolongs wound healing and increases the chances of surgical site infection. Thus, blood glucose monitoring coupled with treatment of dysglycemia is vital to reduce morbidity and mortality. ${ }^{24}$

Our study conducted in 1,000 patients showed that duration of starvation was unnecessarily prolonged in $52.4 \%$ of patients. Fasting guidelines have been repeatedly updated by many organizations including the ASA ${ }^{25}$ In spite of this, fasting is prolonged in many countries as per previous studies. ${ }^{3,26-31}$ Aroni et $\mathrm{al}^{26}$ observed durations between 8 and 37 hours, Hong and Yoon ${ }^{3}$ found that patients starved for up to 14 hours, Gul et $\mathrm{al}^{29}$ in their review showed mean fasting time to be 12 to 14 hours, while Gunawardhana ${ }^{28}$ found fasting to solids to be 13.86 hours with range of 8 to 18 hours. Hamid ${ }^{27}$ performed an interventional study and proved that simple interventions like staff training, patient information leaflets, and posters significantly improved patient comfort.

Overall incidence of hypoglycemia was found to be $23.3 \%$ in our study with a distribution of $27.2 \%$ patients including $34.95 \%$ children in elective surgery group and $33.37 \%$ patients including $8.73 \%$ children in emergency surgery group. The adult incidence is similar to that reported by Hong and Yoon ${ }^{3}$ who studied the impact of longer preoperative fasting time in nondiabetic patients of more than 60 years of age and found 17.6 to $32.4 \%$ of patients showing blood glucose level of $<79 \mathrm{mg} / \mathrm{dL}$ at 8 to 14 hours preoperative fasting. Gul et al ${ }^{29}$ enumerated hypoglycemia as one of the adverse effects of prolonged 
fasting preoperatively. However, Sharma et $\mathrm{al}^{32}$ found no incidence of hypoglycemia in children who fasted for various periods from midnight as against control cases with $10 \mathrm{~mL}$ per $\mathrm{kg} 5 \%$ dextrose water orally 3 to 4 hours before the expected time of start of surgery. A diurnal variation in blood sugar levels, inclusion of emergency cases, timing of sampling by finger-prick method may explain the high incidence of hypoglycemia found in our study. The incidence of $2.23 \%$ hyperglycemia was lower than $7.9 \%$ found in a study by Frisch et $\mathrm{al}^{33}$ who studied effects of hyperglycemia in noncardiac surgery patients probably due to inclusion of pediatric patients in our study.

Our study showed statistically significant difference between the mean blood glucose levels of subgroups based on age (higher in adults), type of surgery (higher in emergency surgery), and were higher in patients who received steroid, Isolyte $\mathrm{P}, 6 \% \mathrm{HES}$, or blood transfusion, and lower with nonglucose-containing fluids like NS (Tables 3 and 4). Ringer's lactate (RL) may have shown no correlation due to hepatic conversion to glucose.

Young male patients posted for emergency surgery showed higher blood glucose level, which may be due to higher levels of stress and more frequent incidence of trauma and subsequent glucocorticoid use for head injuries. Roberts et $\mathrm{al}^{34}$ concluded age and male gender to be independent predictors of high fasting blood glucose, from a prospective study on prevalence of hyperglycemia in nondiabetic population. Desborough ${ }^{8}$ described the pathophysiology of trauma and surgical stress and their role in hyperglycemia by activation of sympathetic system and pituitary hormone release. Singh et $\mathrm{al}^{7}$ found the frequency of stress hyperglycemia to be $47.89 \%$ from a prospective observational analysis of 126 nondiabetic patients of hip fracture. Preoperative hyperglycemia can adversely affect intraoperative blood glucose levels, ${ }^{22}$ postoperative surgical site infection, ${ }^{2}$ and wound healing. Though surgical stress causes intraoperative hyperglycemia in most patients, induction of anesthesia may lead to hypoglycemia by suppressing the excessive sympathetic response, and hence, blood glucose needs to be measured and managed aggressively in patients with preoperative hyperglycemia.

Use of systemic glucocorticoids and higher pain and anxiety score were directly related to incidence of hyperglycemia. van Raalte and Diamant ${ }^{11}$ studied in detail the diabetogenic mechanisms of glucocorticoids. Hwang and Weiss ${ }^{12}$ gave an estimate of $40 \%$ incidence of new-onset diabetes in patients administered steroids. Abdelmalak et al ${ }^{9}$ showed increase in blood glucose after dexamethasone administration in nondiabetic patients.

In our study, the infusion of nondextrose-containing IVFs showed association to lower blood glucose levels though the difference was statistically insignificant compared with that of recipients of dextrose-containing IVFs and to that of nonrecipients. The present study also showed that males between 18 and 40 years showed high blood glucose levels on receiving 6\% HES and females posted for emergency surgery showed high blood glucose levels with preoperative blood transfusion, while males who received NS had a lower blood glucose level. Murty et $\mathrm{al}^{18}$ found that $6 \%$ HES increases blood glucose levels but to physiological extent, while RL has no effect on blood glucose. Jung et a ${ }^{19}$ found statistically insignificant rise in blood sugar with $6 \%$ HES infusion and RL. Cheng et $\mathrm{al}^{20}$ did a retrospective study regarding impact of IVFs and blood transfusion over blood glucose levels but found no significant difference. Tilak et $\mathrm{al}^{22}$ found significant association of blood administration with maximum intraoperative blood glucose level and total amount of IVF with maximum postoperative blood glucose level. Eder and Chambers ${ }^{21}$ related both hypoglycemia and hyperglycemia to blood transfusion.

As no antibiotics affecting blood sugar were administered to the study population, the correlation could not be established. Other limitations of our study were higher number of adults, males, and emergency surgeries included in the study population due to convenient, consenting, consecutive sampling. More studies with larger samples of matched cohorts need to be carried out to establish the correlation of various factors with incidence of preoperative hypoglycemia and hyperglycemia in nondiabetic patients coming for surgery.

\section{CONCLUSION}

Our study detected significant correlation of hypoglycemia with adult females, preoperative NS infusion, apart from an expected correlation with extremes of age, duration of starvation, and emergency surgery. Thus, patients in these groups should be carefully monitored and treated for hypoglycemia preoperatively. Also hyperglycemia showed a significant correlation in young adult males posted for emergency surgery apart from expected correlation with prior steroid treatment, blood transfusion, $6 \%$ HES infusion, high stress, and pain. Thus, preoperative blood glucose monitoring is recommended mandatorily for all patients posted for emergency surgery irrespective of age or gender. It is also recommended for elective pediatric and geriatric surgery patients, patients with high anxiety and/or pain, increased duration of starvation, preoperative administration of steroid, NS, 6\% HES, or blood.

\section{REFERENCES}

1. Amiel SA, Gale E. Physiological responses to hypoglycemia. Counterregulation and cognitive function. Diabetes Care 1993 Dec;16(Suppl 3):48-55. 
2. Takesue Y, Tsuchida T. Strict glycemic control to prevent surgical site infections in gastroenterological surgery. Ann Gastroenterol Surg 2017 Apr;1(1):52-59.

3. Hong $\mathrm{M}$, Yoon $\mathrm{H}$. Influence of pre-operative fasting time in blood glucose in older patients. J Korean Acad Nurs 2011 Apr;41(2):157-164.

4. Basu R, Breda E, Oberg AL, Powell CC, Dalla MC, Basu A, Vittone JL, Klee GG, Arora P, Jensen MD, et al. Mechanisms of the age-associated deterioration of glucose intolerance: contribution of alteration in insulin secretion, action and clearance. Diabetes 2003 Jul;52(7):1738-1748.

5. Ko GTC, Wai HPS, Tang JSF. Effects of age on plasma glucose levels in non-diabetic Hong Kong Chinese. Croat Med J 2006 Oct;47(5):709-713.

6. Shah M, Zahoorullah Haq TU, Akhtar T. The effect of preanaesthetic fasting on blood glucose level in children undergoing surgery. J Pak Med Assoc 1990 Oct;40(10):243-245.

7. Singh VK, Haria JM, Jain SK. Stress hyperglycemia - an observational study". Int J Sci Stud 2014 Jun;2(3):63-66.

8. Desborough JP. The stress response to trauma and surgery. $\mathrm{Br}$ J Anaesth 2000 Jul;85(1):109-117.

9. Abdelmalak BB, Bonilla AM, Yang D, Chowdary HT, Gottlieb A, Lyden SP, Sessler DI. The hyperglycemic response to major noncardiac surgery and the added effect of steroid administration in patients with and without diabetes. Anesth Analg 2013 May;116(5):1116-1122.

10. Fathallah N, Slim R, Larif S, Hmouda H, Ben Salem C. Drug-induced hyperglycaemia and diabetes. Drug Saf 2015 Dec;38(12):1153-1168.

11. van Raalte DH, Diamant M. Steroid diabetes: from mechanism to treatment? Neth J Med 2014 Feb;72(2):62-72.

12. Hwang JL, Weiss RE. Steroid-induced diabetes: a clinical and molecular approach to understanding and treatment. Diabetes Metab Res Rev 2014 Feb;30(2):96-102.

13. Bodnar T, Starr K, Halter JB. Linezolid-associated hypoglycemia in a 64-year-old man with type 2 diabetes. Am J Geriatr Pharmacother 2011 Feb;9(1):88-92.

14. Viswanathan P, Iarikov D, Wassel R, Davidson A, Nambiar S. Hypoglycemia in patients treated with linezolid. Clin Infect Dis 2014 Oct;59(8):e93-e95.

15. Johnson PC, Vaduganathan M, Phillips KM, O'Donnell WJ. A triad of linezolid toxicity: hypoglycemia, lactic acidosis, and acute pancreatitis. Proc (Bayl Univ Med Cent) 2015 Oct;28(4):466-468.

16. Aspinall SL, Good CB, Jiang R, McCarren M, Dong D, Cunningham FE. Severe dysglycemia with the fluoroquinolones: a class effect? Clin Infect Dis 2009 Aug;49(3):402-408.

17. Kelesidis T, Canseco E. Quinolone-induced hypoglycemia: a life-threatening but potentially reversible side effect. Am J Med 2010 Feb;123(2):e5-e6.

18. Murty SS, Kamath SK, Chaudhari LS. Effects of hydroxyethyl starches on blood sugar levels: a randomized double blind study. Indian J Anaesth 2004 Jun;48(3):196-200.

19. Jung KT, Shim SB, Choi WY, An TH. Effect of hydroxyethyl starch on blood glucose levels. Korean J Anesthesiol 2016 Aug;69(4):350-356.
20. Cheng KW, Chen $\mathrm{CL}$, Cheng YF, Tseng CC, Wang $\mathrm{CH}$, Chen YS, Wang CC, Huang TL, Eng HL, Chiu KW, et al. Dextrose in the banked blood products does not seem to affect the blood glucose levels in patients undergoing liver transplantation. World J Gastroenterol 2005 May;11(18): 2789-2791.

21. Eder AF, Chambers LA. Noninfectious complications of blood transfusion. Arch Pathol Lab Med 2007 May;131(5): 708-718.

22. Tilak V, Schoenberg C, Castro III AF, Sant M. Factors associated with increases in glucose levels in the perioperative period in non-diabetic patients. Open J Anesthesiol 2013;3(3):176-185.

23. Shi J, Dong B, Mao Y, Guan W, Cao J, Zhu R, Wang S. Traumatic brain injury and hyperglycemia, a potentially modifiable risk factor. Oncotarget 2016 Oct;7(43):71052-71061.

24. Kwon S, Thompson R, Dellinger P, Yanez D, Farrohki E, Flum D. Importance of perioperative glycaemic control in general surgery: a report from the surgical care and outcomes assessment program. Ann Surg 2013 Jan;257(1):8-14.

25. ApfelbaumJL,Agarkar M, Connis RT, Coté CJ, Nickinovich DG, Warner MA. Practice guidelines for preoperative fasting and the use of pharmacologic agents to reduce the risk of pulmonary aspiration: application to healthy patients undergoing elective procedures an updated report by the American Society of Anesthesiologists Task Force on preoperative fasting and the use of pharmacologic agents to reduce the risk of pulmonary aspiration. Anesthesiology 2017 Mar;126(3):376-393.

26. Aroni P, do Nascimento LA, Fonseca LF. Assessment strategies for the management of thirst in the post-anesthetic recovery room. Acta Paul Enferm 2012 Jan;25(4):530-536.

27. Hamid S. Pre-operative fasting - a patient centered approach. BMJ Quality Improvement Reports 2014 Oct;2(2):u605.w1252.

28. Gunawardhana AI. Knowledge, attitudes and practice of preoperative fasting guidelines in the National Hospital of Sri Lanka. Sri Lankan J Anaesthesiol 2012 Jul;20(2):92-95.

29. Gul A, Andsoy II, Ustundag H, Ozkaya BO. Assessment of preoperative fasting time in elective general surgery. JMHM 2013;1(1):1-8.

30. Andrew-Romit JJ, Van de Mortel TF. Ritualistic preoperative fasting: is it still occurring and what can we do about it? J Perioper Nurs Aust. 2011 Sep;24(1):14-19.

31. Arun BG, Korula G. Pre-operative fasting in children: an audit and its implication in a tertiary care hospital. J Anaesthesiol Clin Pharmacol 2013 Jan-Mar;29(1):88-91.

32. Sharma V, Sharma R, Singh G, Gurkhoo S, Qazi S. Preoperative fasting duration and incidence of hypoglycaemia and haemodynamic response in children. J Chem Pharm Res 2011 Jan;3(6):382-391.

33. Frisch A, Chandra P, Smiley D, Peng L, Rizzo M, Gatcliffe C, Hudson M, Mendoza J, Johnson R, Lin E, et al. Prevalence and clinical outcome of hyperglycemia in the peri-operative period in noncardiac surgery. Diabetes Care 2010 Aug;33(8):1783-1788.

34. Roberts D, Meakem T, Dalton C, Haverstick D, Lynch C III. Prevalence of hyperglycemia in a pre-surgical population. Internet J Anesthesiol 2006;12(1):1-7. 